Caries Res 1990;24(suppl 1):43

\title{
Dental Caries in Developed and Developing Countries
}

\section{Members of Workshop C}

Dr. I. Moller Chairman, WHO, Copenhagen, Denmark

Mrs. S.A. Williams Raporteur, School of Dentistry, University

of Leeds, England Prof. A.-K. Holm Presenter, University of Umeå, Sweden

Participants

Mr. I.P. Bell Kellogg Co., Manchester, England

Prof. A. Chosack Hebrew University, Jerusalem, Israel Miss E. Davenport London Hospital

Medical College, London

England

Dr. G.A. Jenkins Wrigley Co. Ltd., Plymouth, England

Dr. A. Kingman National Institute for Dental Research,

Bethesda, Md.

Prof. E. Mizrahi Highlands North, Johannesburg, South

Africa

Prof. J.M. Navia University of Alabama, Birmingham, Ala.

Prof. D. O’Mullane University Dental Hospital and School,

Cork, Eire

Prof. S. Poulsen University Dental School, Aarhus, Denmark

Dr. T.S. Rodgers University Department of Dentistry,

Adelaide, Australia

Prof. Curzon: Ladies and gentlemen, may we continue with the next presentation. This paper on 'Diet and Caries in High-Risk Groups in Developed and Developing Countries' and will be given by Prof. Holm. The chairman of the session and the workshop is Dr. Ingolf Moller from the WHO unit in Copenhagen. It is my pleasure to call upon Dr. Moller to continue the session. Dr. Moller: It is my pleasure to ask Prof. Holm to present her paper to open this workshop. Prof. Holm has much experience in this area and was recently involved in a number of studies on dental caries in third world countries, as well as with immigrant populations. 